\title{
Complementary feeding patterns of Filipino infants and toddlers lack diversity, especially among children from poor households
}

Emma F. Jacquier ${ }^{1}$, Imelda Angeles-Agdeppa ${ }^{2}$, Yvonne M. Lenighan ${ }^{1 *}$ (D, Marvin B. Toledo ${ }^{2}$ and Mario V. Capanzana

\begin{abstract}
Background: Consumption of nutritionally adequate complementary foods is essential for optimal growth and development of infants and toddlers, including those in developing countries. The aim of this study was to describe the food and beverage consumption patterns among 6-23.9 month old Filipino infants and toddlers, by household wealth.

Methods: Data from 1087 infants and toddlers from the 2013 National Nutrition Survey were included. Dietary intake data was assessed using a $24 \mathrm{Hr}$ recall and population food intakes were stratified into pre-defined wealth categories.

Results: Breast milk, infant formula, powdered milk and rice were the most commonly consumed foods and beverages across the age groups. Several differences in complementary feeding by wealth status were observed. Infants from poor households (69\%) reported significantly greater consumption of human milk, than those from rich households (42\%) who reported a significantly greater consumption of infant/toddler formula (Poor: $22 \%$, Rich: $56 \%)(P<0.05)$. A higher percentage of toddlers from rich households consumed protein-containing foods, cookies and cakes. There was a significant difference in vegetable consumption in 12-17.9 month old children (Poor: 17\%, Rich: 31\%; $P=0.021$ ). Human milk and formula were the top contributors to energy in 6-17.9 month old children, while rice was the top energy contributor in 18-23.9 month old children.

Conclusion: Milk and rice were the main dietary components in all Filipino children, contributing up to 60\% of energy in the infants from poorer households. Consumption of protein-containing foods and vegetables were typically lower in poorer households. Interventions are required to enable caregivers of young Filipino children to provide complementary foods of high nutritional quality, particularly among children from the poor households.
\end{abstract}

Keywords: Complementary feeding, Infants, Children, Philippines

\footnotetext{
* Correspondence: yvonne.lenighan@rd.nestle.com

${ }^{1}$ Nestlé Research, Vers-Chez-Les-Blanc, 1000 Lausanne, Switzerland

Full list of author information is available at the end of the article
}

(c) The Author(s). 2020 Open Access This article is licensed under a Creative Commons Attribution 4.0 International License, which permits use, sharing, adaptation, distribution and reproduction in any medium or format, as long as you give appropriate credit to the original author(s) and the source, provide a link to the Creative Commons licence, and indicate if changes were made. The images or other third party material in this article are included in the article's Creative Commons licence, unless indicated otherwise in a credit line to the material. If material is not included in the article's Creative Commons licence and your intended use is not permitted by statutory regulation or exceeds the permitted use, you will need to obtain permission directly from the copyright holder. To view a copy of this licence, visit http://creativecommons.org/licenses/by/4.0/. The Creative Commons Public Domain Dedication waiver (http://creativecommons.org/publicdomain/zero/1.0/) applies to the data made available in this article, unless otherwise stated in a credit line to the data. 


\section{Key messages}

A greater number of mothers from the poor households complied with the WHO recommendation to breastfeed, and children from the poor households were breastfed for longer than the rich households.

Milk consumption among older toddlers in the poor and middle wealth households decreased with age compared to toddlers from the rich households.

Consumption of nutrient poor foods is more common among infants and toddlers from the low wealth households compared to those from the rich households.

\section{Background}

The nutritional quality of appropriate complementary foods is an important factor in the healthy growth and development of infants and young children [1]. During this period of early childhood, dietary habits and preferences begin to form, and caregivers must pay special attention to the choices and quality of foods offered to meet nutritional needs of the growing child. However, access to a variety of affordable and nutritious complementary foods may be challenging for households of limited means. Socioeconomic status has been recognised as a determinant of health [2] and individuals with higher socioeconomic status are more likely to have access to, and consume, healthier diets [3]. Hence, guidelines for complementary feeding aimed at low- and middle-income countries encourage feeding practices that promote consumption of nutrient dense foods [1].

Despite the economic growth of the Philippines over recent years, the National Nutrition Survey (NNS) reported that among infants aged 1 year old about $36.2 \%$ of children are stunted and that $20.8 \%$ are underweight [4]. There is also a high prevalence of anaemia (40.5\%) in infants aged 6 months to less than 1 year [4]. Indeed, studies from the Philippines found that inadequate nutrient intakes in Filipino schoolchildren were more marked among those from poor families. Infants and young children in the Philippines also had a high prevalence of inadequate nutrient intakes [5].

At present, there has been no comprehensive assessment of socioeconomic differences in complementary feeding patterns in a nationally representative sample of Filipino infants and toddlers. Regional studies conducted to date have focused on sub-populations in Cebu and urban areas [6-10] and report sub-optimal nutrient intakes during the complementary feeding period. Furthermore, an association between complementary feeding practices and anaemia, stunting, iron and vitamin A deficiencies have also been identified [7]. The aim of this study was to describe the food and beverage consumption patterns among 6-23.9 month old Filipino infants and toddlers, and the associated impact on nutrient intakes, by household wealth status. This study provides novel results on the role of household wealth in determining nutrient adequacy in this vulnerable population.

\section{Methods \\ Participants}

The National Nutrition Survey (NNS) is a nationally representative, cross-sectional, epidemiological survey of the health and nutritional status of the Filipino population. The survey covers all 17 regions and 80 provinces of the country and applies a three-stage sampling system which enables full geographical coverage in both rural and urban areas. Survey response rate was high (87.7\%) among the 35, 825 households surveyed. This study includes 1087 infants and young children aged 6-23.9 months who participated in the 2013 NNS in the Philippines. The protocol and survey instruments were approved by the Ethics committee of the Food and $\mathrm{Nu}$ trition Research Institute (FNRI) and informed consent was obtained from all households that participated. Anthropometric data (height, length and weight) were measured in the participant's home, and the World Health Organization-Child Growth Standards were used to assess the nutritional status of the children, based on weight and height measurements. The socioeconomic status of the household was determined based on the possession of certain items e.g. vehicles, gadgets and household appliances. This data was then applied to classify households into wealth categories [4]. For the purpose of the food group analysis, the population was split into three categories; poor, middle and rich, however, for the in-depth analysis on usual nutrient intakes the poor and rich categories were further characterised into poor, poorest, rich and richest.

\section{Dietary intake data collection}

A full description of the methods of the Filipino 2013 NNS has been previously described $[4,5)$. All dietary interviews were carried out in-person with the primary caregiver of the child. Trained dietitians collected data on all foods and beverages consumed using a structured 24 hour $(\mathrm{Hr})$ dietary recall. A single $24 \mathrm{Hr}$ recall is not reflective of habitual intakes of a person, however evidence suggests that two $24 \mathrm{Hr}$ recalls in a proportion of the population can provide an approximate measure of habitual/long-term diet. Therefore, a second $24 \mathrm{Hr}$ recall was collected on a non-consecutive day from $50 \%$ of the households and was used to estimate usual nutrient intakes. Usual intakes were calculated using SAS software and the validated National Cancer Institute (NCI) method to calculate usual intakes was applied to calculate means and standard deviations [11, 12]. This method has been validated $[13,14]$ and is considered to be reflective of long term intakes within a given time period e.g. childhood. Amounts of foods and beverages 
were estimated using common household measures, and were converted into grams using a portion-to-weight list developed by FNRI for the survey.

The Individual Dietary Evaluation System (IDES), developed by FNRI, was used to process the dietary records and to estimate nutrient intakes from the $24 \mathrm{Hr}$ recalls [5]. Quality control of the data collected occurred at both the food level (amounts reported and coding to appropriate food groups) and at nutrient level to exclude implausible intakes [15]. Breast milk consumption was estimated using the child's age and assigned volumes as in other national nutrition surveys of the infant population [16]. Foods were assigned to a food grouping system consisting of 85 food groups similar to those used in other dietary intake surveys of the infant and toddler population but adapted to include foods common in the local food culture [16].

\section{Statistical methods}

The percentage of infants and young children consuming each food group was calculated by wealth category, as previously described [5]. The percent contribution of energy from food groups was calculated, at the population level, by summing the energy provided by each food group and dividing by the total energy intake by age and wealth category. Chi-squared tests were applied to examine the relationships between age, household wealth category and food group consumption. Usual nutrient intakes were estimated using the PC-SIDE software (Version 1.0) developed by Iowa State University (Ames, IA, USA) and data were analysed using Stata Version 13 (StataCorp, College Station, TX, USA). Since dietary variety increases at 12 months of age when children are eating more foods of the family table, the decision was taken to examine nutrient intakes starting from 12 months and also to examine, more closely, usual nutrient intakes by household wealth status.

\section{Results}

The characteristics of the study population are presented in Table 1 . The population was split almost equally by gender and age. In terms of wealth status the population was divided as follows; $50 \%$ from poor households; $20 \%$ from middle-class households and 30\% from rich households. Additionally, approximately $54 \%$ of the children were from urban areas, and $46 \%$ resided from a rural setting. Approximately $5-6 \%$ of the children were underweight, $5-11 \%$ stunted, 2-4\% wasted, and $4 \%$ overweight.

\section{Milk types by age and household wealth category}

The percent of consumers by milk types and by wealth category is presented in Table 2.
Table 1 Sample demographics of the 6-23.9 month Filipino study population

\begin{tabular}{|c|c|c|}
\hline & & Percent \\
\hline \multicolumn{3}{|l|}{ Gender } \\
\hline Boy & & 50.1 \\
\hline Girl & & 49.9 \\
\hline \multicolumn{3}{|c|}{ Age } \\
\hline 6-11.9 months old & & 33.0 \\
\hline 12-17.9 months old & & 33.0 \\
\hline 18-23.9 months old & & 34.0 \\
\hline \multicolumn{3}{|c|}{ Wealth categories } \\
\hline Poor & & 50.0 \\
\hline Middle & & 20.1 \\
\hline Rich & & 29.9 \\
\hline \multicolumn{3}{|c|}{ Region } \\
\hline Urban & & 54.1 \\
\hline Rural & & 45.9 \\
\hline \multicolumn{3}{|c|}{ Anthropometry } \\
\hline Underweight & & 16.6 \\
\hline Stunting & & 22.8 \\
\hline Wasting & & 8.5 \\
\hline Normal weight & & 48.1 \\
\hline Overweight & & 3.9 \\
\hline
\end{tabular}

Among 6-11.9 month old infants, there were significant differences by wealth status. Breast milk was consumed by $69 \%$ of infants from the poor households, compared to $42 \%$ in the rich households $(P<0.001)$. In contrast, infant formula was consumed by $22 \%$ of $6-$ 11.9 month old infants from the poor households and $56 \%$ of children from rich households $(P<0.001)$. Breast milk was consumed by $54 \%$ of $12-17.9$ month olds from the poor households, compared to $24 \%$ from the rich households $(\mathrm{P}<0.001)$. Powdered milk was consumed by $34 \%$ of children from the poor households in this age group, compared to $15 \%$ from the rich households $(P=$ 0.001 ). Toddler/preschooler formula was consumed by $10 \%$ of $12-17.9$ month olds from the poor households, and $47 \%$ from the rich households $(P<0.001)$. In the older age group (18-23.9 month olds), the percentage of milk (all types) consumers in the poor and middle households were lower than those from rich households $(P<0.001)$. There was a wide variation in breast milk consumption in 18-23.9 month old children, ranging from $35 \%$ in children from the poor households to $19 \%$ from the rich households. Similar to the younger group, toddler/preschooler formula was consumed by $7 \%$ of 
Table 2 Milk consumption (expressed as percent consuming) of Filipino 6-23 month olds, by wealth category

\begin{tabular}{|c|c|c|c|c|c|c|c|c|c|c|c|c|}
\hline & \multicolumn{4}{|c|}{ 6-11.9 mo } & \multicolumn{4}{|c|}{$12-17.9 \mathrm{mo}$} & \multicolumn{4}{|c|}{$18-23.9 \mathrm{mo}$} \\
\hline & Poorest & Middle & Richest & & Poorest & Middle & Richest & & Poorest & Middle & Richest & \\
\hline & $n=170$ & $n=71$ & $n=105$ & $P^{\dagger}$ & $n=183$ & $n=68$ & $n=101$ & $P^{\dagger}$ & $n=175$ & $n=74$ & $n=114$ & $P^{\dagger}$ \\
\hline All milk & 96 & 100 & 98 & 0.162 & 91 & 93 & 97 & 0.204 & 70 & 81 & 95 & $<0.001$ \\
\hline Breast milk & 69 & 63 & 42 & $<0.001$ & 54 & 44 & 24 & $<0.001$ & 35 & 27 & 19 & 0.061 \\
\hline Powdered milks & 17 & 24 & 18 & 0.449 & 34 & 19 & 15 & 0.001 & 34 & 42 & 29 & 0.242 \\
\hline Formula & 25 & 31 & 62 & $<0.001$ & 13 & 40 & 61 & $<0.001$ & 7 & 23 & 48 & $<0.001$ \\
\hline Infant & 22 & 31 & 56 & $<0.001$ & 3 & 9 & 15 & 0.001 & 0 & 1 & 5 & 0.076 \\
\hline Toddler/preschooler & 4 & 0 & 7 & 0.088 & 10 & 31 & 47 & $<0.001$ & 7 & 22 & 43 & $<0.001$ \\
\hline
\end{tabular}

${ }^{\dagger}$ Chi-square test for independence between wealth groups, $P<0.05$ considered significant

18-23.9 month olds from the poor households, compared to $43 \%$ from the rich households $(\mathrm{P}<0.001)$.

\section{Food groups by age and household wealth category}

There were notable differences in food group consumption by wealth status among 6-11.9 month old infants (Table 3). Infant cereal (grain-based cereal with nutrient fortification) was consumed by $7 \%$ of 6-11.9 month old infants from the poor households, compared to $23 \%$ of infants from the middle-class households and 19\% from the rich households $(P=0.001)$. Among $12-17.9$ month old children, consumption of eggs was greater in middle and rich households $(P=0.015)$. Consumption of cookies and cakes was higher in 12-17.9 month old children from rich households, while sugar sweetened beverage (SSBs) consumption was higher in infants from the poor households $(P<0.05)$. There was no significant difference in rice consumption between the age or wealth groups, however consumption of bread and noodles were greater among 1217.9 month old toddlers from the rich households, compared to the poor households $(\mathrm{P}<0.05)$. Protein-rich foods were more likely to be consumed by $12-17.9$ month old toddlers from the rich households; pork (13\% rich, $2 \%$

Table 3 Food consumption (expressed as percent consuming) of Filipino 6-23.9 month olds, by wealth category

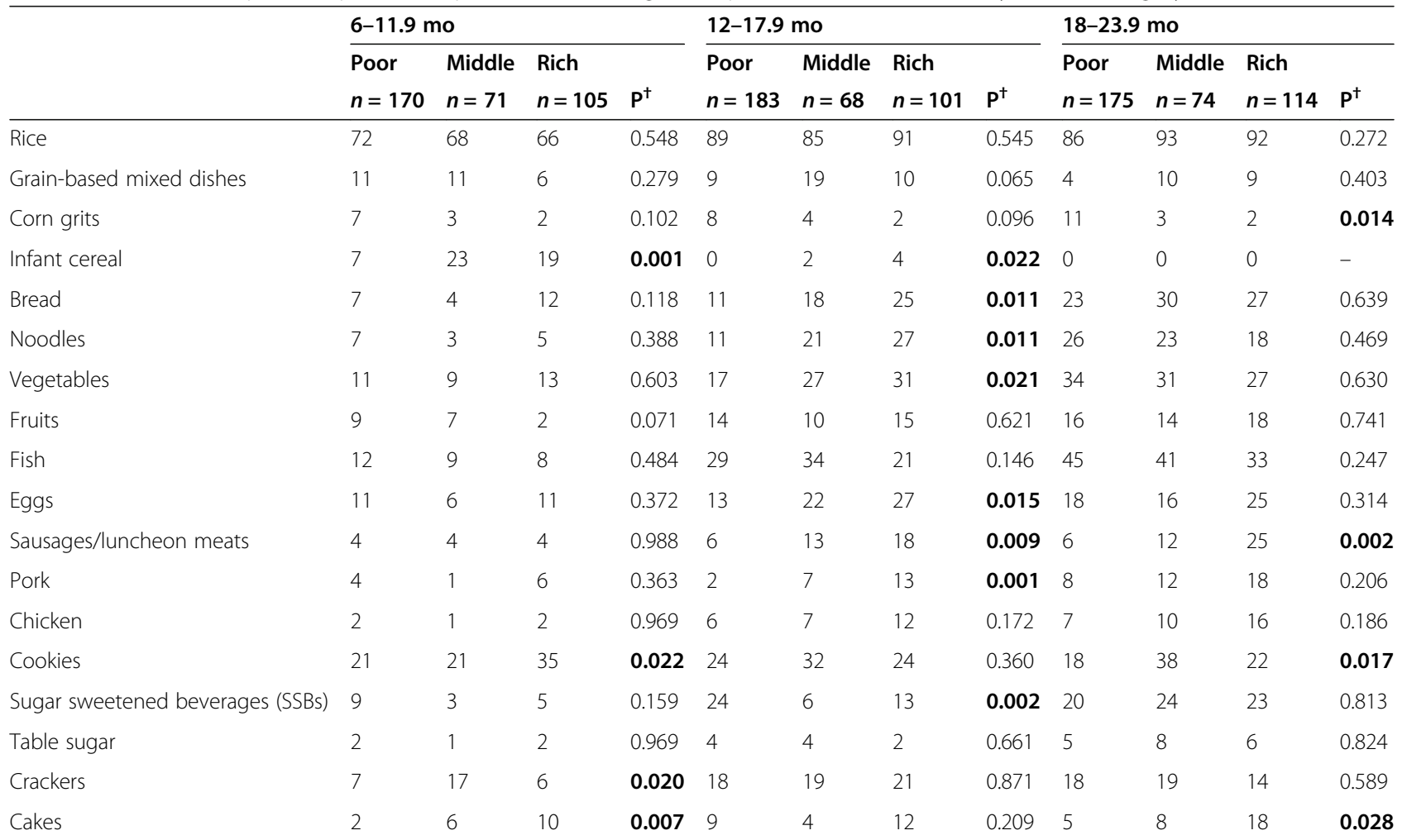


poor), sausages/luncheon meat (18\% rich, $6 \%$ poor) and eggs $(27 \%$ rich, $13 \%$ poor $)(\mathrm{P}<0.05)$. Vegetable consumption was significantly greater among toddlers from the rich households $(P=0.021)$. While, percentage consumption of SSBs was greater among 12-17.9 month olds from the poor households (24\%) compared to the rich households $(13 \%)(P=0.002)$. Similar consumption patterns of rice and grits were observed among the 12-17.9 month old and 18-23.9 month old toddlers. A greater percentage of 18-23.9 month old toddlers from richer households consumed sausages/luncheon meat compared to those from middle-income and poorer households $(\mathrm{P}=0.002)$. There was an apparent difference in consumption of cookies $(P=0.017)$ and cakes $(P=0.028)$ also, with $38 \%$ of $18-23.9$ month old toddlers from middle households consuming cookies and 18\% of toddlers from the rich households consuming cakes.

\section{Total daily energy intakes by age and household wealth category}

The contribution of food to daily energy intakes by wealth status are presented in Fig. 1. Among 6-11.9 month olds, breast milk was the greatest contributor to energy intakes in infants from the poor households (44\%). In contrast, infant formula provided the greatest energy contribution in 6-11.9 month old infants from the rich households (50\%). Rice provided 16\% of energy intakes in poor households, compared to $8 \%$ in infants from rich households, while infant cereal provided greater contributions in 6-11.9 month old infants from rich households than the poorer households.
Similar to the 6-11.9 month old infants, breast milk (27\%) and rice $(23 \%)$ were the greatest contributors to energy intakes in 12-17.9 month old toddlers from the poor households, while toddler/preschooler formula (26\%) and rice $(16 \%)$ were the greatest contributors to energy intakes in toddlers from rich households. Powdered milk contributed to $16 \%$ of energy intakes in 12 17.9 month old toddlers in the poor households, compared to $8 \%$ of intakes in the rich households, and infant formula contributed to $11 \%$ of energy in the rich households, compared to $3 \%$ in the poor households. Rice provided the greatest energy contributions in 18-23.9 month old toddlers from the poor households (32\%), with toddler formula providing the greatest contributions in the rich households (19\%). Breast milk (16\%) and powdered milks (11\%) were the second and third highest contributors in the poor households, compared to rice $(18 \%)$ and powdered milks $(15 \%)$ in the rich households. Bread and noodles contributed to energy intakes across the three wealth groups.

\section{Usual nutrient intakes in $\mathbf{1 2 - 2 3 . 9 m o ~ t o d d l e r s ~ b y ~}$ household wealth category}

The usual nutrient intakes of $12-23.9$ mo toddlers are presented in Table 4. Protein and total fat intakes were higher in toddlers from the rich and richest households, both in grams/day and as a percentage of total energy. Intakes of vitamin $C$, riboflavin, niacin, vitamin $B_{6}$, folate, vitamin $B_{12}$, vitamin $D$ and vitamin $\mathrm{E}$ were higher among toddlers from the wealthiest households. Similarly, intakes of calcium, iron,

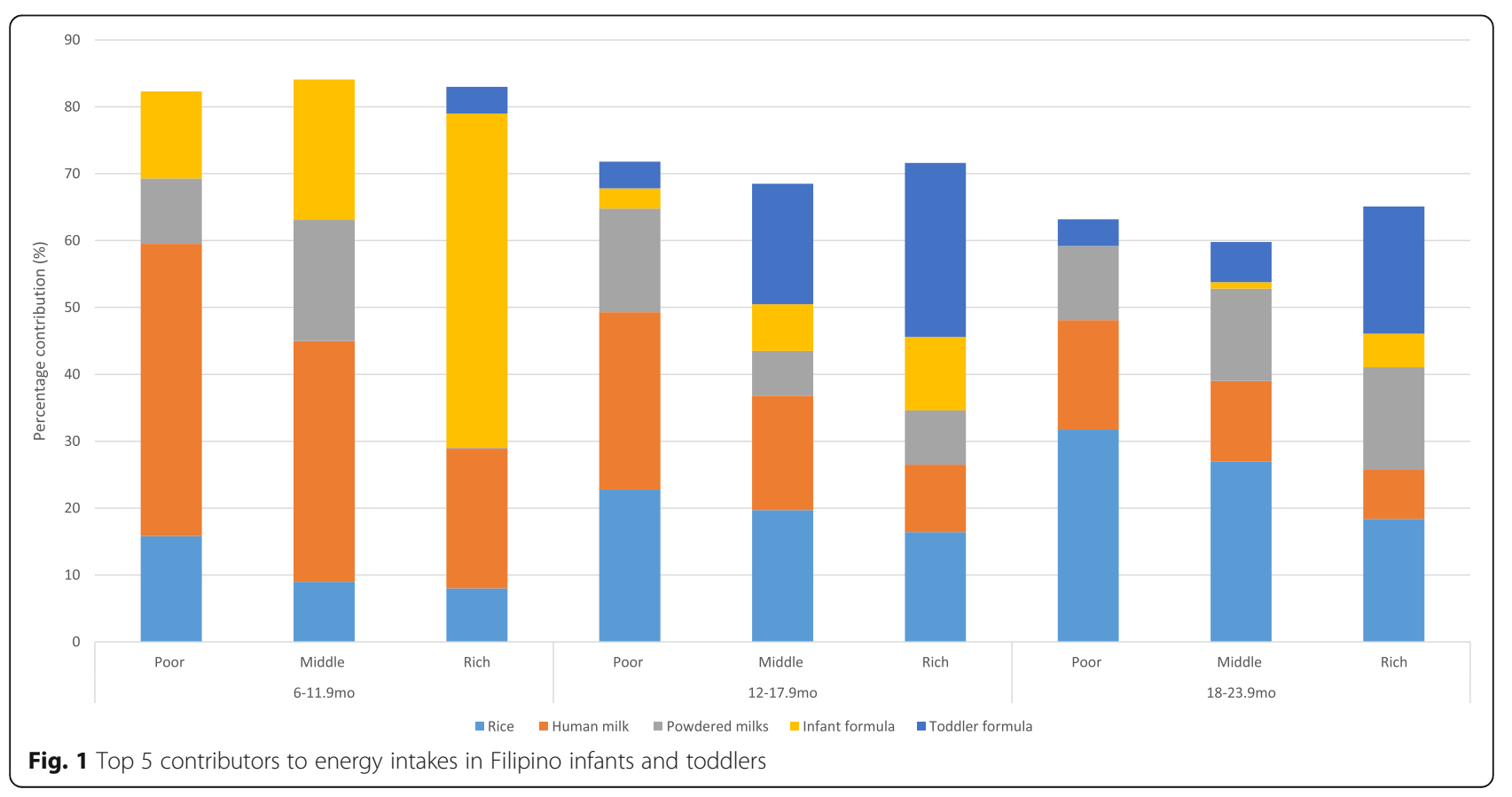


Table 4 Usual nutrient intakes in a subpopulation of Filipino 12-23.9 month old children, by wealth category

\begin{tabular}{|c|c|c|c|c|c|}
\hline & $\begin{array}{l}\text { Poorest } \\
n=208\end{array}$ & $\begin{array}{l}\text { Poor } \\
n=141\end{array}$ & $\begin{array}{l}\text { Middle } \\
n=139\end{array}$ & $\begin{array}{l}\text { Rich } \\
n=116\end{array}$ & $\begin{array}{l}\text { Richest } \\
n=92\end{array}$ \\
\hline Carbohydrate (g/d) & $108.2 \pm 3.3$ & $109.2 \pm 4.1$ & $112.4 \pm 4.2$ & $114 \pm 4.3$ & $116 \pm 4.4$ \\
\hline Total sugars (g/d) & $31.3 \pm 1.3$ & $33 \pm 1.6$ & $30.8 \pm 1.5$ & $33.7 \pm 2.6$ & $29.3 \pm 2.5$ \\
\hline Dietary fiber (g/d) & $2.3 \pm 0.1$ & $2.2 \pm 0.1$ & $2.3 \pm 0.1$ & $2.4 \pm 0.1$ & $2.4 \pm 0.2$ \\
\hline Protein (g/d) & $19 \pm 0.6$ & $22.8 \pm 1$ & $21.8 \pm 0.8$ & $27.5 \pm 1.3$ & $27.7 \pm 1.4$ \\
\hline Total fat (g/d) & $19.7 \pm 0.6$ & $25 \pm 1$ & $24 \pm 0.9$ & $30.5 \pm 1.5$ & $31.6 \pm 1.5$ \\
\hline SFA (g) & $8.7 \pm 2.6$ & $8 \pm 0.4$ & $8 \pm 0.4$ & $9.4 \pm 0.5$ & $8.1 \pm 0.6$ \\
\hline MUFA (g) & $5.6 \pm 0.2$ & $8.4 \pm 0.6$ & $6.4 \pm 0.4$ & $9.7 \pm 0.8$ & $6.9 \pm 0.6$ \\
\hline PUFA (g) & $1.7 \pm 0.1$ & $2.7 \pm 0.2$ & $2.1 \pm 0.1$ & $2.9 \pm 0.2$ & $2.2 \pm 0.2$ \\
\hline \multicolumn{6}{|c|}{ As percentage of total energy } \\
\hline Carbohydrate (\%) & $62.5 \pm 0.7$ & $58 \pm 0.7$ & $59.8 \pm 0.6$ & $55.2 \pm 0.9$ & $54.5 \pm 0.9$ \\
\hline Protein (\%) & $11.2 \pm 0.2$ & $11.8 \pm 0.2$ & $11.4 \pm 0.2$ & $12.8 \pm 0.3$ & $12.6 \pm 0.3$ \\
\hline Total Fat (\%) & $26.2 \pm 0.7$ & $29.9 \pm 0.6$ & $29.7 \pm 0.6$ & $31.9 \pm 0.8$ & $32.6 \pm 0.7$ \\
\hline \multicolumn{6}{|l|}{ Vitamins } \\
\hline Vitamin A ( $\mu \mathrm{gRE} / \mathrm{d})$ & $195.7 \pm 12.2$ & $315 \pm 31.1$ & $197.1 \pm 18.6$ & $335.4 \pm 40$ & $159.8 \pm 27.2$ \\
\hline Vitamin C (mg/d) & $21.2 \pm 1$ & $23.7 \pm 1.8$ & $32.2 \pm 2.9$ & $37.7 \pm 3$ & $55.7 \pm 4.4$ \\
\hline Thiamine (mg/d) & $0.3 \pm 0.02$ & $0.4 \pm 0.02$ & $0.4 \pm 0.03$ & $0.5 \pm 0.03$ & $0.7 \pm 0.05$ \\
\hline Riboflavin (mg/d) & $0.5 \pm 0.03$ & $0.8 \pm 0.07$ & $0.7 \pm 0.1$ & $1.1 \pm 0.1$ & $1.2 \pm 0.1$ \\
\hline Niacin $(\mathrm{mg} / \mathrm{d})$ & $4.2 \pm 0.1$ & $4.4 \pm 0.2$ & $5.3 \pm 0.3$ & $5.8 \pm 0.3$ & $7.7 \pm 0.5$ \\
\hline Vitamin B6 (mg) & $0.3 \pm 0.02$ & $0.6 \pm 0.1$ & $0.5 \pm 0.03$ & $0.6 \pm 0.05$ & $1.1 \pm 0.1$ \\
\hline Folate (DFE $\mu \mathrm{g}$ ) & $92.9 \pm 6.2$ & $85.4 \pm 4.7$ & $118.6 \pm 9.3$ & $107.8 \pm 8.2$ & $161.9 \pm 14$ \\
\hline Vitamin B12 (mg) & $0.9 \pm 0.04$ & $0.8 \pm 0.1$ & $1.1 \pm 0.1$ & $1.2 \pm 0.1$ & $1.6 \pm 0.1$ \\
\hline Vitamin D (mg) & $1.2 \pm 0.1$ & $1.4 \pm 0.2$ & $2.5 \pm 0.2$ & $2.7 \pm 0.3$ & $5.2 \pm 0.7$ \\
\hline Vitamin E (mg) & $1.5 \pm 0.1$ & $1.5 \pm 0.1$ & $2.5 \pm 0.3$ & $2.1 \pm 0.2$ & $3.6 \pm 0.4$ \\
\hline \multicolumn{6}{|l|}{ Minerals } \\
\hline Calcium (mg/d) & $291.4 \pm 16.5$ & $447.3 \pm 35.1$ & $413.8 \pm 30$ & $632.9 \pm 52.7$ & $768.2 \pm 62.7$ \\
\hline Phosphorus (mg/d) & $311.7 \pm 13.4$ & $453.2 \pm 30.5$ & $389.8 \pm 21.8$ & $544.1 \pm 40.1$ & $491.6 \pm 33.1$ \\
\hline Iron (mg/d) & $3.2 \pm 0.1$ & $3.5 \pm 0.2$ & $4.6 \pm 0.3$ & $5.7 \pm 0.4$ & $9 \pm 0.8$ \\
\hline Sodium (mg/d) & $469.5 \pm 23.7$ & $504.6 \pm 21.2$ & $474.2 \pm 27$ & $576.7 \pm 32.4$ & $555.7 \pm 33.9$ \\
\hline Zinc (mg) & $3.1 \pm 0.2$ & $5.3 \pm 1$ & $3.8 \pm 0.2$ & $3.7 \pm 0.2$ & $5.2 \pm 0.4$ \\
\hline Magnesium (mg) & $49 \pm 1.9$ & $49.2 \pm 2.3$ & $57.5 \pm 3$ & $63.5 \pm 4.2$ & $73.4 \pm 4.8$ \\
\hline Potassium (mg) & $456.5 \pm 153$ & $441.8 \pm 16.1$ & $562.7 \pm 25.7$ & $606.3 \pm 45.6$ & $693.1 \pm 47$ \\
\hline Selenium (mg) & $31.2 \pm 1.3$ & $27.3 \pm 1.3$ & $32.5 \pm 1.7$ & $31.8 \pm 1.6$ & $30 \pm 1.9$ \\
\hline
\end{tabular}

magnesium and potassium were higher in toddlers from the richest households.

\section{Discussion}

The objective of this analysis was to describe the food and beverage consumption patterns among 6-23.9 month old Filipino infants and toddlers, and the associated impact on nutrient intakes, by household wealth status. The analysis highlights differences in food group consumption patterns, according to wealth status and provides insight into complementary feeding behaviours that may drive inequities in nutrient intake in infants and toddlers in the Philippines.

The prevalence of breastmilk consumption in this population has been previously reported by Denney et al. as $60 \%$ in 6-11.9 month old infants and $37 \%$ of 12-23.9 month old toddlers [5]. This analysis showed that there was higher breastmilk consumption among infants and toddlers from poorer households (Infants; Poor: 69\%, Rich: 42\%), and as a result breastmilk had a greater contribution to energy among these infants and toddlers (Infants; Poor: 44\% Rich: 21\%). Overall, the prevalence of breastfeeding in Filipino infants is sub- 
optimal and does not adhere to the guidelines of continued, on-demand breastfeeding until 2 years of age and beyond [1]. Nonetheless, the situation is better than that reported in national surveys from other geographies e.g. China (44\% 0-5.9mo) [17] and Mexico (15\% 0-3.9mo) [18]. Public health strategies, including educational campaigns and the availability of lactation consultants, are required to further increase the rates of breastfeeding among Filipino mothers.

In the current study, breast milk contributes $7-40 \%$ of energy intakes of infants and toddlers between 6 and 24 months, depending on the child's stage and wealth status, with infant/toddler formula providing from 1 to $50 \%$ of energy intakes. Additionally, rice contributed from 8 to $23 \%$ of energy intakes in this population. However, breast milk and rice are low in minerals such as iron and zinc, and infant need complementary foods, in particular, those that provide iron, zinc and calcium, from the age of 6 months $[19,20]$. Infants typically consume relatively small amounts of complementary foods between 6 and 11.9 months, therefore, the nutrient density of these foods needs to be high [21]. The current analysis suggests that consumption of nutrient dense food at this age is low, therefore educational strategies are needed to inform mothers of the importance of consuming nutrient dense foods at this early life stage. An extensive study examining Filipino infant and child feeding (6-23 months of age) in urban areas reported that children who are breastfed were more likely to be anaemic or iron deficient after 6 months of age than those receiving fortified foods [7]. This is similar to results reported in other countries including India, China and Japan [2224]. Fortified young child beverages provide a source of iron among Filipino infants $(6-11.9 \mathrm{mo})$ and toddlers (12-23.9mo), respectively [5]. However, consumption of these products was more prevalent in infants and toddlers from higher income households. This may, in part, explain some of the differences in nutrient intakes according to household wealth category.

Rice is the most commonly consumed $(94.8 \%)$ food in the Philippines, and is also the primary source of energy, protein, iron, thiamin and niacin [4]. In the current study the percentage contribution of rice to total daily energy, was consistently higher among children from the poorest households in infants and toddlers. This was reflected by poorer intakes of vitamins and minerals in toddlers from poorer backgrounds. However, a recent paper by Denney et al. in the same population, identified inadequate of protein and B vitamins in Filipino infants and toddlers at population level [5]. Ideally, the mandatory rice with vitamins and minerals in the Philippines could provide a public health opportunity to improve nutrient intakes, particularly among children from poorer households. For example, a study among school kids revealed significant reduction in anaemia after a 120 day supervised fortified lunch feeding program [25]. Unfortified complementary foods that are plant-based generally do not provide sufficient key nutrients such as iron, zinc and calcium in adequate amounts for very young children in developing countries [26]. The current analysis identified low intakes of iron, zinc and calcium in young Filipino children, particularly in those from poor households. Therefore, initiatives to support fortification of commonly consumed foods could help to close this gap in nutrient intakes.

In general, infant cereal consumption is low in the Philippines, with the exception of a sub-population from the rich households. In the current study, iron-fortified infant cereal, as recommended in complementary feeding by the American Academy of Paediatricians [27], was lacking from the diet, except among 6\% of 6$11.9 \mathrm{mo}$ infants from the middle and rich households. The current study identified a very limited diversity of foods in the diets of Filipino infants and children, with less than 5 foods making up $80 \%$ of the diet in 6-11.9 month olds and $60 \%$ of the diet in 18-23.9 month olds. Nutrient-dense protein foods such as eggs, pork and chicken were more likely to be consumed by children from richest households. Whereas, fish was more likely to be consumed by children from low wealth households. Improving access to nutritious or fortified foods for children, particularly breast-fed infants such as infant cereal, could help to improve micronutrient intakes. However, it must be noted, that even in the U.S., iron and zinc were identified as problem nutrients [16] despite the widespread availability of fortified foods for infants. Therefore, ensuring adequate nutrient supply in complementary feeding is clearly complex and requires further detailed study in order to examine how young children can meet their nutrient needs in these challenging circumstances.

In the current study, SSBs were more likely to be consumed by infants and young toddlers from the poorest households. However, SSBs were consumed at approximately equal prevalence across wealth categories in 1823.9 month olds. Since the nutrient needs, according to body weight, of infants and young children are very high [27] there is typically no room in the diet for nutrientpoor foods such as SSBs. In the current study, infants were more likely to consume fruit juice and powdered chocolate milk than other types of SSBs. In order to help combat the nutritional inadequacies in the Philippines, fruit juice and chocolate milk are often fortified and have been shown to be among the top sources of micronutrients in the diets of Filipino children [5]. Fortified fruit juice has been effective at reducing the basal level of iron deficient anaemia in Filipino school children from 100 to $13 \%$ [28, 29]. However, it must be noted 
that unpublished data from the most recent Philippines National Nutrition Survey shows that the prevalence of overweight has increased in 3-5 year old children between 2015 and 2018, with a similar trend observed in school-aged children (Preliminary Results National Nutrition Survey 2018, Food and Nutrition Research Institute). Evidence suggests that excess weight gain in infancy, of which consumption of a poor diet (low in fruit and vegetables and high in sugar) or a high calorie diet, in early childhood could be a contributing factor, has been associated with increased risk of developing obesity and associated comorbidities in later life [30-32]. The current study demonstrated that the diet of Filipino infants is rich in carbohydrates, with limited protein intakes and low adherence to the local Filipino Pinggang Pinoy recommendation for frequent consumption of fruit and vegetables. This may be due to a number of factors including high cost, limited access to fresh fruit and vegetables, poor nutrition knowledge and family members' food preferences [33]. Therefore, the importance of fruit and vegetables, meat, poultry, fish and eggs, should be emphasised in Filipino households, regardless of wealth status. Public health authorities may wish to investigate methods to improve accessibility to such foods, particularly among low-income households.

This study presents a very comprehensive evaluation of complementary feeding patterns of Filipino infants and young children. It relied on nationally representative data from the National Nutrition Survey in 2013. Several limitations are noted. The dietary intake estimates for the infants and young children were based on reports by parents, and may have included inaccuracies leading to over- or under-estimation of food intakes. The data were collected in 2013, and it is possible that new foods on the market in the Philippines, especially fortified foods, could have resulted in subsequent improvements in the nutrient intake estimates of young children. Furthermore, we used a single $24 \mathrm{~h}$ recall to assess food group intakes, and this may not fully capture habitual dietary intakes. Dietary supplements were not included in the analysis and, if used, may have also increased nutrient intakes in this population.

\section{Conclusion}

Strategies aiming to make fortified foods affordable and accessible to low-income populations, and the widespread use of vitamin and mineral supplements of young children and their breastfeeding mothers could help to improve nutrient intakes. This study provided a detailed assessment of nutrient intakes in this population according to wealth category, but additional assessments of foods available in the local food supply would be required to determine if food fortification or supplementation would be the most appropriate strategy for meeting nutrient gaps. In addition, environmental and conservational issues need to be considered when evaluating nutrient sources for low-income and vulnerable populations in the Philippines.

In light of the high rates of anaemia and inadequate nutrient intakes among Filipino infants, future research should focus on determining how best to meet the nutritional needs of young Filipino children. Further work is needed to identify potential targets for food fortification, and to clarify the impact of fortification (or supplementation) with single or multiple nutrients is needed. Diet modelling studies on the impact of fortification of commonly consumed foods or supplementation may shed light on the feasibility of potential strategies aimed at improving nutrient intakes, particularly among infants and toddlers from poor households.

\section{Abbreviations \\ 24Hr: 24 hour; NNS: National Nutrition Survey; FNRI: Food and Nutrition Research Institute; IDES: Individual Dietary Evaluation System; SSBs: Sugar- sweetened beverages}

\section{Acknowledgements}

We acknowledge the contribution of Royce Ann Octavio, Kristine Biona and Regina Rodriguez for building food composition tables and food groups, along with Mark Lester Cayadong, and Glen Melvin Gironella for work in data management and programming. We would also like to thank the field workers who assisted in data collection and the caregivers and children who participated in the study. We also thank Liya Denney for her guidance.

\section{Authors' contributions}

E.F.J designed the analysis, interpreted the data, wrote the manuscript and has the final responsibility for the contents. M.B.T conducted the analysis. Y.M.L and I.A.A, contributed to the data analysis, data interpretation and manuscript editing. M.V.C. contributed to the critical review and editing of the manuscript. All authors read and finally approved this manuscript for submission.

\section{Funding}

The National Nutrition Survey including was funded by the Government of the Philippines. This included design of the study and collection and analysis of the data. This analysis of food consumption by wealth status, interpretation of the data and writing of the manuscript was funded by the Nestlé Institute of Health Sciences, Lausanne, Switzerland.

\section{Availability of data and materials}

The datasets supporting the conclusions of the study are included in the article. Any additional data will be available on request. The datasets used and/or analyzed during the current study are available from the FNRI on reasonable request.

\section{Ethics approval and consent to participate}

The protocol and survey instruments were approved by the Ethics committee of the Food and Nutrition Research Institute (FNRI) and written informed consent was obtained from all households that participated (through parent / guardian for children under 10 years old). Written informed consent was obtained from a parent/guardian for participants under 16 years old.

\section{Consent for publication}

NA.

\section{Competing interests}

E.F.J. and Y.M.L. are employees of Nestec. Ltd. (Nestlé Institute of Health Sciences), Lausanne, Switzerland. The opinions expressed in the article are 
those of the authors alone and do not necessarily reflect the views and recommendations of their affiliations.

\section{Author details}

${ }^{1}$ Nestlé Research, Vers-Chez-Les-Blanc, 1000 Lausanne, Switzerland. ${ }^{2}$ Department of Science and Technology, Food and Nutrition Research Institute, Manila, The Philippines.

\section{Received: 26 February 2020 Accepted: 31 August 2020}

Published online: 26 October 2020

\section{References}

1. World Health Organisation. Guiding principles for complementary feeding of the breastfed child. 2004. https://www.who.int/nutrition/publications/ guiding_principles_compfeeding_breastfed.pdf?ua=1.

2. Mayen AL, Marques-Vidal P, Paccaud F, Bovet P, Stringhini S. Socioeconomic determinants of dietary patterns in low- and middle-income countries: a systematic review. Am J Clin Nutr. 2014;100(6):1520-31.

3. Darmon N, Drewnowski A. Does social class predict diet quality? Am J Clin Nutr. 2008:87(5):1107-17.

4. Food and Nutrition Institute. Philippine Nutrition Facts and Figures 2013: 8th National Nutrition Survey Overview. Metro Manila: Food and Nutrition Institute; 2015

5. Denney L, Angeles-Agdeppa I, Capanzana M, Toledo M, Donohue J, Carriquiry A. Nutrient intakes and food sources of Filipino infants, toddlers and young children are inadequate: findings from the National Nutrition Survey 2013. Nutrients. 2018;10(11):1730.

6. Perlas LA, Gibson RS, Adair LS. Macronutrient and selected vitamin intakes from complementary foods of infants and toddlers from Cebu, Philippines. Int J Food Sci Nutr. 2004;55(1):1-15.

7. Rohner F, Bradley AW, Grant JA, Elizabeth AY, Lebanan MAO, Rayco-Solon P et al. Infant and young child feeding practices in urban Philippines and their associations with stunting, anemia, and deficiencies of iron and vitamin A. Food Nutr Bull. 2013;34(2_suppl1):S17-34.

8. Wright M, Bentley M, Mendez M, Adair L. The interactive association of dietary diversity scores and breast-feeding status with weight and length in Filipino infants aged 6-24 months. Public Health Nutr. 2015:10:1762-73.

9. Kennedy GL, Pedro MR, Seghieri C, Brouwer I, Nantel G. Dietary diversity score is a useful Indicator of micronutrient intake in non-breast-feeding Filipino children. J Nutr. 2007;137(2):472-7.

10. Tengco LW, Rayco-Solon P, Solon JA, Sarol JN Jr, Solon FS. Determinants of anemia among preschool children in the Philippines. J Am Coll Nutr. 2008; 27(2):229-43.

11. Tooze JA, Midthune D, Dodd KW, Freedman LS, Krebs-Smith SM, Subar AF, et al. A new statistical method for estimating the usual intake of episodically consumed foods with application to their distribution. J Am Diet Assoc. 2006;106(10):1575-87.

12. Dodd KW, Guenther PM, Freedman LS, Subar AF, Kipnis V, Midthune D, et al. Statistical methods for estimating usual intake of nutrients and foods: a review of the theory. J Am Diet Assoc. 2006;106(10):1640-50.

13. Tooze JA, Kipnis V, Buckman DW, Carroll RJ, Freedman LS, Guenther PM, et al. A mixed-effects model approach for estimating the distribution of usual intake of nutrients: the NCI method. Stat Med. 2010;29(27):2857-68.

14. Freedman LS, Guenther PM, Dodd KW, Krebs-Smith SM, Midthune D. The population distribution of ratios of usual intakes of dietary components that are consumed every day can be estimated from repeated 24-hour recalls. J Nutr. 2010;140(1):111-6.

15. López-Olmedo N, Carriquiry AL, Rodríguez-Ramírez S, Ramírez-Silva I, Espinosa-Montero J, Hernández-Barrera L, et al. Usual intake of added sugars and saturated fats is high while dietary Fiber is low in the Mexican population-4. J Nutr. 2016;146(9):1856S-65S.

16. Roess AA, Jacquier EF, Catellier DJ, Carvalho R, Lutes AC, Anater AS, et al. Food consumption patterns of infants and toddlers: findings from the Feeding Infants and Toddlers Study (FITS) 2016. J Nutr. 2018;148(suppl_3): 1525S-35S

17. Hong Qin LZ, Zhang L, Zhang W, Li L, Deng X, Tian D, Deng J, Hu G. Prevalence of breastfeeding: findings from the first health service household interview in Hunan Province, China. Int J Environ Res Public Health. 2017;14: 150

18. Deming DM, Afeiche MC, Reidy KC, Eldridge AL, Villalpando-Carrión S. Early feeding patterns among Mexican babies: findings from the 2012 National
Health and nutrition survey and implications for health and obesity prevention. BMC Nutrition. 2015:1(1):40.

19. World Health Organization/United Nation Children's Fund. Global Strategy for Infant and Young Child Feeding. Geneva: WHO Press; 2003. https://apps. who.int/iris/bitstream/handle/10665/42590/9241562218.pdf? sequence=1. Accessed 9 Sept 2019.

20. Dewey KG. Nutrition, growth, and complementary feeding of the brestfed infant. Pediatr Clin N Am. 2001;48(1):87-104

21. United Nations Children's Fund. Programming guide: infant and young child feeding. New York: UNICEF; 2011. https://www.unicef.org/nutrition/ files/Final_IYCF_programming guide_2011.pdf. Accessed 21 Aug 2019.

22. Chandyo RK, Henjum S, Ulak M, Thorne-Lyman AL, Ulvik RJ, Shrestha PS, et al. The prevalence of anemia and iron deficiency is more common in breastfed infants than their mothers in Bhaktapur, Nepal. Eur J Clin Nutr. 2016:70(4):456-62.

23. Clark KM, Li M, Zhu B, Liang F, Shao J, Zhang Y, et al. Breastfeeding, mixed, or formula feeding at 9 months of age and the prevalence of iron deficiency and iron deficiency anemia in two cohorts of infants in China. J Pediatrics. 2017;181:56-61.

24. Amano I, Murakami A. Prevalence of infant and maternal anemia during the lactation period in Japan. Pediatrics Intl. 2019;61(5):495-503.

25. Angeles-Agdeppa C, Barba CVC, Florentino RF, Takanashi K. Efficacy of ironfortified rice in reducing anemia among schoolchildren in the Philippines. Int J Vitam Nutr Res. 2008;78(2):74-86.

26. Motuma Adimasu Abeshu AL, Geleta B. Complementary Feeding: Review of Recommendations, Feeding Practices, and Adequacy of Homemade Complementary Food Preparations in Developing Countries - Lessons from ethiopia. Front Nutr. 2016;3:41.

27. American Academy of Pediatrics. Pediatric Nutrition. Itasca: American Academy of Pediatrics; 2014

28. FAO. The State of Food Security and Nutrition. 2019. http://www.fao.org/3/ ca5162en/ca5162en.pdf. Accessed 17 Sept 2019.

29. Imelda Angeles-Agdeppa CRM, Capanzana MV. Fortified juice drink improved iron and zinc status of schoolchildren. Asia Pac J Clin Nutr. 2011; 20(4):535-43.

30. Reilly JJ, Armstrong J, Dorosty AR, Emmett PM, Ness A, Rogers I, et al. Early life risk factors for obesity in childhood: cohort study. BMJ. 2005:330(7504): 1357

31. Rooney BL, Mathiason MA, Schauberger CW. Predictors of obesity in childhood, adolescence, and adulthood in a birth cohort. Mater Child Health J. 2011;15(8):1166-75.

32. Baidal JAW, Locks LM, Cheng ER, Blake-Lamb TL, Perkins ME, Taveras EM. Risk factors for childhood obesity in the first 1,000 days: a systematic review. Am J Preventive Med. 2016:50(6):761-79.

33. Marilou M. Lopez-Madrid CCSA, Consuelo L. Orense, Charmaine a. Duante, Robby Carlo a. tan, Mario V. Capanzana. Awareness of and adherence to the food based dietary guidelines among household meal planners in the Philippines. Philippine J Sci. 2018;147(3):523-35.

\section{Publisher's Note}

Springer Nature remains neutral with regard to jurisdictional claims in published maps and institutional affiliations.

Ready to submit your research? Choose BMC and benefit from:

- fast, convenient online submission

- thorough peer review by experienced researchers in your field

- rapid publication on acceptance

- support for research data, including large and complex data types

- gold Open Access which fosters wider collaboration and increased citations

- maximum visibility for your research: over $100 \mathrm{M}$ website views per year

At BMC, research is always in progress.

Learn more biomedcentral.com/submissions 